\title{
THE INFLUENCE OF FOREST MANAGEMENT ON FUTURE FOREST STRUCTURE FOLLOWING A MOUNTAIN PINE BeEtle OUTBREAK IN LODGEPOLE PINE STANDS IN NORTHWESTERN WYOMING
}

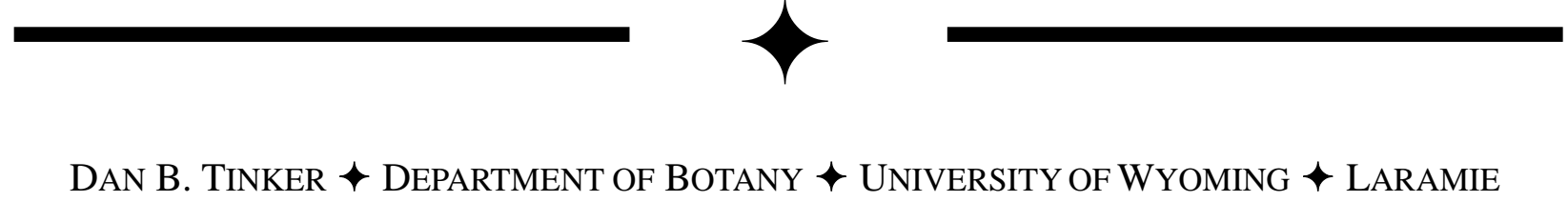

\section{$\uparrow \quad$ INTRODUCTION}

Forest managers in the western U.S. are currently confronted with a bark beetle epidemic that is unprecedented in extent, severity, and duration. Several species of native bark beetle including the mountain pine beetle (MPB), spruce beetle, western balsam bark beetle, and Douglas-fir beetle are simultaneously affecting over 5 million ha of forest in the Intermountain West (Logan et al. 2003, Hicke et al. 2006). Estimates of the total area affected by the current bark beetle outbreak are updated annually, typically using aerial surveillance and manual mapping techniques. However, these estimates are often inaccurate and do not provide quantitative information on stand-level beetle activity and/or tree mortality. More importantly, these annual estimates of "spread" of the epidemic do not provide any information on the abundance of the surviving understory trees, which may be substantial, nor do they provide information on post-disturbance tree seedling establishment. This "advance forest regeneration" represents the future forests in these regions. Therefore, understanding the current structure of the forests is critical for making predictions about future structure and function.

Effects of bark beetle outbreaks on predisturbance stand structure (tree density, basal area, and species composition) have been well documented in the Rocky Mountain region for mountain pine beetle in ponderosa and lodgepole pine (Romme et al. 1986, Dordel et al. 2008, Axelson et al. 2009), for spruce beetle and western balsam bark beetle in spruce-fir forests (Kulakowski et al. 2003, McMillan et al. 2003), and for DFB in Douglas-fir forests (Negron et al. 1999, McMillan and Allen 2003). While forest regeneration following fire has been well documented for many types of fire and forests, forest regeneration following bark beetle outbreak is not well understood, and differs from fire in several ways. In contrast to stand-replacing fires, which typically kill all trees in a stand, including small trees, following a bark beetle outbreak the understory and the small trees that grow there are rarely killed. Thus, the release of understory survivors by overstory removal is often the major mechanism of post-beetle outbreak forest regeneration (Nigh et al. 2008, Boggs et al. 2008). Romme et al. (1986) found that understory survival was a critical mechanism for regeneration of lodgepole pine stands following mountain pine beetle outbreaks in Wyoming. More recently, Nigh et al. (2008) documented post-beetle regeneration in lodgepole pine forests in British Columbia. Notably, they found that ALL stands showed at least some level of advance regeneration, and over half of the stands had 1000 or more individual trees per hectare.

As future forests develop, it is important to learn from the past, specifically to investigate the influence of past forest management on overstory mortality from bark beetles and and advance regeneration. Unfortunately, little work has been done to understand how previous forest management actions, such as timber harvest, pre-commercial thinning, or fuel reduction projects have influenced the mortality of mature trees in the overstory, or the composition and abundance of advance regeneration. This pilot study investigated how past forest 
management treatments may have influenced bark beetle impacts and post-outbreak understory advance regeneration in the Shoshone National Forest (SNF), Wyoming.

Understanding these questions is important for helping natural resource management agencies make informed decisions. Both elected officials and the general public are putting pressure on forest managers to "do something" about the outbreak. There is ongoing controversy over whether hands-off management promotes diversity and resiliency, while others believe commercial timber treatments should be allowed in roadless and wilderness areas because of uncertainty about whether the forests will recover without human-intervention. Previous research on forest responses to beetle-killed trees in other regions has shown that trees grow back naturally to adequate stocking levels (Collins et al. 2010, Boggs et al. 2008). For this pilot study, we focused on one primary question: How do pre-canopy tree density and species composition differ from post-outbreak advance regeneration density and species composition?

\section{$\uparrow \quad$ METHODS}

During the summer of 2011, we sampled a total of 12 stands in the Shoshone National Forest in northwest Wyoming. All of these stands were dominated by lodgepole pine (Pinus contorta var. latifolia). Ten of the plots had been previously managed by the USFS, and had been subjected to some level of pre-commercial thinning, and two of the plots had not received any appreciable management treatments. Historical records were provided by the USFS to identify specific past treatments of the managed plots and the local USFS staff also provided welcome assistance in the selection of the plots. All study plots were selected to have similar site characteristics with respect to soil type and topography. The two unmanaged stands were located in USFS roadless areas and we used caution to avoid stands that had experienced fire suppression or tie-hacking activities.

Sampling occurred in a 0.25 -hectare plot in each stand to measure overstory and advance regeneration density and composition. Three, 50x4 m belt transects were established in each plot and were used to record tree species, condition (live/dead and beetle activity), diameter at breast height, tree height and sapling basal diameter and height within each plot. We also collected tree increment cores from the ten largest trees in the stand to determine stand age.

\section{$\uparrow \quad$ RESULTS}

\section{Managed stands}

In the ten managed stands, pre-outbreak canopy density averaged 908 stems/ha, and ranged from 400-2216 stems/ha. Approximately $92 \%$ of the pre-outbreak canopy was composed of lodgepole pine, with whitebark pine, subalpine fir, and Engelmann spruce comprising the remaining $8 \%$ (Figure 1). Advance regeneration, composed of both saplings and seedlings of all species, averaged 1326 stems/ha, and ranged from a low of 317 stems/ha to 2682 stems/ha in the most dense stand. In contrast to the pre-outbreak canopy, only $\sim 44 \%$ of the advance regeneration was lodgepole pine, with whitebark pine representing $35 \%$ of all advance regeneration. The remaining $21 \%$ was mostly aspen and subalpine fir, with a small amount of Engelmann spruce (Figure 1).

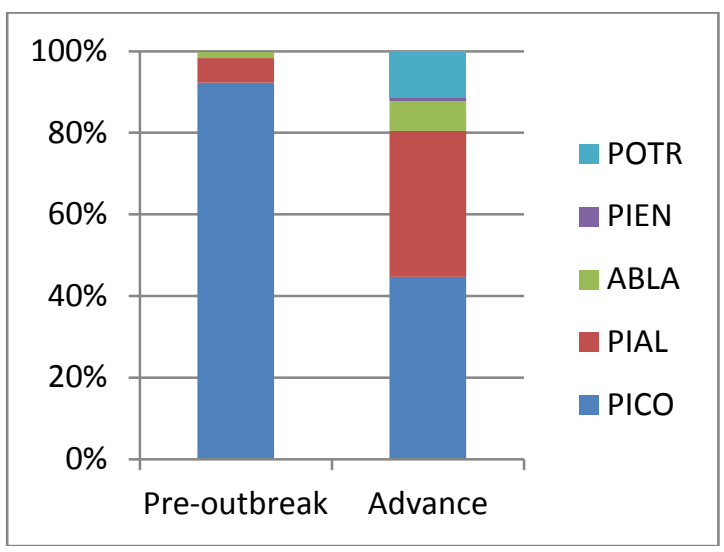

Figure 1. Comparison of proportions of tree species in Preoutbreak and Post-outbreak (Advance Regeneration) in MANAGED stands in the SNF (POTR - Populus tremuloides; PIEN - Picea engelmannii; ABLA - Abies lasiocarpa; PIAL - Pinus albicaulis; PICO - Pinus contorta).

\section{Unmanaged stands}

In the two unmanaged stands, pre-outbreak canopy density averaged 758 stems/ha, and ranged from 633-883 stems/ha. Lodgepole pine and Engelmann spruce represented nearly $98 \%$ of the preoutbreak canopy, in nearly equal proportions $(53 \%$ and $45 \%$, respectively; Figure 2). Aspen was the only other tree species represented in the pre-outbreak canopy of unmanaged stands sampled. Advance regeneration averaged 1091 stems/ha, and ranged from 783-1399 stems/ha. The proportion of stems represented by lodgepole pine was considerably smaller than in the pre-outbreak canopy; here, lodgepole pine represented only $18 \%$ of the total 
advance regeneration. Both Engelmann spruce and aspen exhibited an increase in proportion in the advance regeneration, with Engelmann spruce representing nearly 50\% and aspen comprising $28 \%$ of total advance regeneration (Figure 2). The only other tree species represented in the advance regeneration was subalpine fir, and comprised slightly more than $3 \%$ of total advance regeneration.

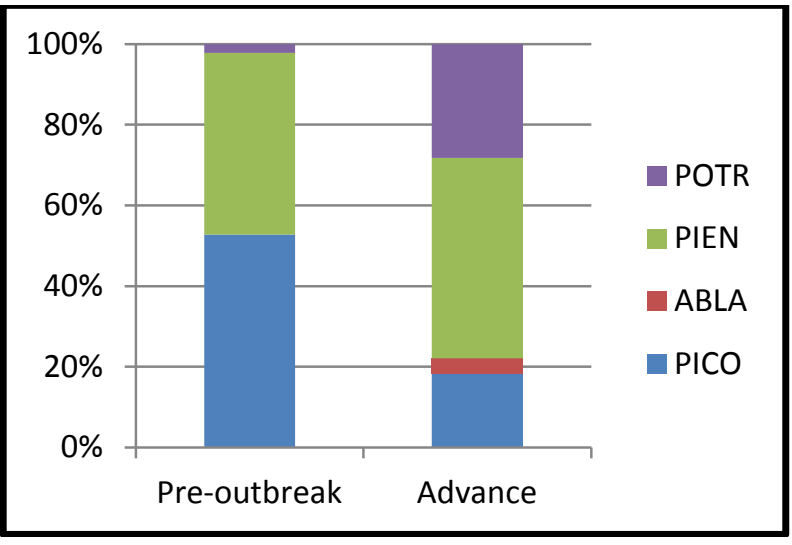

Figure 2. Comparison of proportions of tree species in Preoutbreak and Post-outbreak (Advance Regeneration) in UNMANAGED stands in the SNF (POTR - Populus tremuloides; PIEN - Picea engelmannii; ABLA - Abies lasiocarpa; PIAL - Pinus albicaulis; PICO - Pinus contorta).

\section{Comparison of Managed and Unmanaged Stands}

Average pre-outbreak canopy stem density differed slightly between managed and unmanaged stands, but not substantially (908 vs. 758, respectively). However, lodgepole pine dominated the canopy of managed stands, yet was a co-dominant with Engelmann spruce in the unmanaged stands (Figures 1 and 2). Similarly, advance regeneration was not substantially different between managed and unmanaged stands, although range of stem densities was much larger in the managed stands. Advance regeneration in managed stands was dominated by lodgepole pine, but Engelmann spruce and aspen dominated advance regeneration in the unmanaged stands.

\section{DISCUSSION}

Pre-commercial thinning apparently does little to impact advance regeneration in post-outbreak forest stands in SNF. While the range of seedling/sapling densities was broader in the managed stands, the average stem densities were quite similar between managed and unmanaged stands. These results cannot be directly compared to previous studies investigating the effects of more intensive timber harvesting in lodgepole pine forests. For example, Collins et al. (2011) found that new seedling recruitments were four times higher in postharvest stands than in unharvested stands in Colorado. However, their study involved removal of most of the entire pre-outbreak canopy, which would favor new seedling establishment compared to unharvested stands, especially for shade-intolerant species such as lodgepole pine. However, our findings do agree with a separate study by Collins, et al. (2010), who suggested that post-outbreak regeneration is similar to unharvested (unmanaged) stands.

Our study only provides data from two unmanaged stands, so clearly additional field sampling will be necessary to further clarify trends identified by the current pilot study. Nevertheless, based on these initial findings, and those of other related studies, it appears that post-outbreak forests will be of similar densities to that of pre-outbreak stands, although some changes in the relative proportions of some species may occur. Notably, lodgepole pine will not necessarily be the dominant tree species in post-outbreak forests, but will certainly remain an important component of these forests.

\section{$\uparrow \quad$ ACKNOWLEDGEMENTS}

This study was funded by a grant from the University of Wyoming/National Park Service Research Center Small Grants Program, and by the Wyoming NASA Space Grant Consortium. For their help in the field, we thank Ryan Sims and Nick Spackman. We also thank the staff of the Shoshone National Forest for the assistance with stand location. The UW-NPS Research Station (AMK Ranch) provided housing and logistical support for this study. We also thank Gail Stakes for her help with data entry and analysis.

\section{Literature Cited}

Axelson JN, Alfaro RI, Hawkes BC. 2009. Influence of fire and mountain pine beetle on the dynamics of lodgepole pine stands in British Columbia, Canada. Forest Ecology and Management 257:1874-1882. 
Boggs K, Sturdy M, Rinella DJ, Rinella MJ. 2008. White spruce regeneration following a major spruce beetle outbreak in forests on the Kenai Peninsula, Alaska. Forest Ecology and Management 255:3571-3579.

Collins BJ, Rhoades CC, Hubbard RM, Battaglia, MA. 2011. Tree regeneration and future stand development after bark beetle infestation and harvesting in Colorado lodgepole pine stands. Forest Ecology Management. 261:2168-2175.

Collins BJ, Rhoades CC, Underhill J, Hubbard RM. 2010. Post-harvest seedling recruitment following mountain pine beetle infestation of Colorado lodgepole pine stands: a comparison using historic survey records. Canandian Journal of Forest Research. 40:2452-2456.

Dordel J, Feller MC, Simard SW. 2008. Effects of mountain pine beetle (Dendroctonus ponderosae Hopkins) infestations on forest stand structure in the southern Canadian Rocky Mountains. Forest Ecology and Management. 255:3563-3570.

Hicke JA, Logan JA, Powell J, Ojima DS. 2006. Changing temperatures influence suitability for modeled mountain pine beetle (Dendroctonus ponderosae) outbreaks in the western United States. Journal of Geophysical Research Biogeosciences 111: G02019.

Kulakowski D, Veblen TT, Bebi P. 2003. Effects of fire and spruce beetle outbreak legacies on the disturbance regime of a subalpine forest in Colorado. Journal of Biogeography 30:1445-1456.
Logan JA, Regniere J, Powell JA. 2003. Assessing the impacts of global warming on forest pest dynamics. Frontiers in Ecology and the Environment. 1:130-137.

McMillan JD, Allen KK. 2003. Effects of Douglas-fir beetle (Coleoptera: Scolytidae) infestations on forest overstory and understory conditions in western Wyoming. Western North American Naturalist. 63:498-506.

McMillan JD, Allen KK, Long DF, Harris JL, Negron JF. 2003. Effects of western balsam bark beetle on spruce-fir forests of north-central Wyoming. Western Journal of Applied Forestry. 18:259-266.

Negron JF, Schaupp WC Jr, Gibson KE, Anhold J, Hansen D, Their R, Mocettini P. 1999. Estimating extent of mortality associated with the Douglas-fir beetle in the central and northern Rockies. Western Journal of Applied Forestry. 14:121-127.

Nigh GD, Antos JA, Parish R. 2008. Density and distribution of advance regeneration in mountain pine beetle killed lodgepole pine stands of the montane spruce zone of southern British Columbia. Canadian Journal of Forest Research. 38:2826-2836.

Romme WH, Knight DH, Yavitt JB. 1986. Mountain pine beetle outbreaks in the Rocky Mountains: Regulators of primary productivity? American Naturalist. 127:484494. 